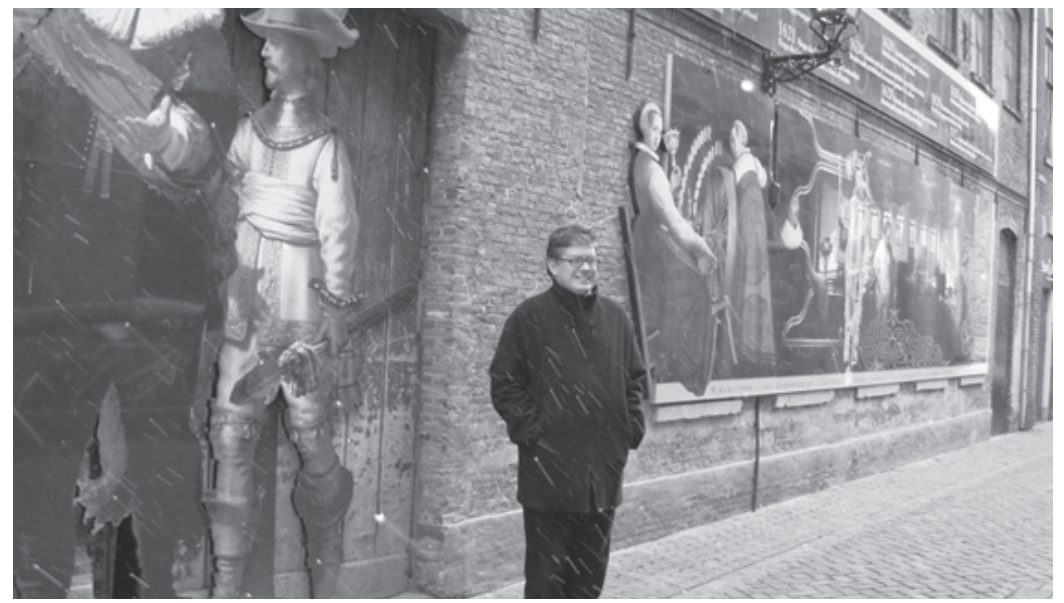

\title{
DA IMAGEM AO TEXTO, DO TEXTO À IMAGEM: CIRCULANDO SENTIDOS
}

\author{
Lúcia Sá Rebello ${ }^{1}$
}

Raúl Antelo, professor titular da Universidade Federal de Santa Catarina, concedeu entrevista para este número da Organon, Literatura e outras linguagens, e, com a agudeza habitual, discorre sobre questões importantes da arte, do cinema e da literatura.

Lúcia Rebello: No âmbito dos estudos comparatistas, o estudo de literatura e outras artes pode contemplar, entre outras, as seguintes relações interdisciplinares: Literatura e Religiosidades; Literatura e Cinema; Literatura e Mass Media; Literatura e Teatro; Literatura e Pintura e Literatura e Música. Os objetivos desses estudos são, do seu ponto de vista, uma via de mão dupla? Ou seja, investigar não só as contribuições que a literatura toma emprestado de outras produções artísticas, mas, também, o processo inverso, observar como e em que medida essas outras áreas do saber fazem uso de temas, produtos e estruturas comuns à literatura?

1 Doutora em Letras pela UFRGS. Professora Associada do Departamento de Letras Clássicas e Vernáculas da UFRGS. 
Raúl Antelo: Creio que há, de fato, uma profusão de trabalhos que abordam, nos últimos dez, vinte anos, as relações entre imagem e texto (o texto na imagem ou seu avesso; o texto após a imagem, a pós-imagem etc.). Seria injusto fazer uma lista exaustiva, mas poderíamos relembrar, certamente, de Hans Belting, e sua Bild-Anthropologie (Fink, 2002); de W.J.T. Mitchell, Picture Theory: Essays on Verbal and Visual Representation (University of Chicago Press, 1994); os trabalhos de Sigrid Weigel sobre Walter Benjamin, desde um livro já traduzido ao espanhol (Cuerpo, imagen y espacio en Walter Benjamin: una relectura. Buenos Aires, Paidós 1999) até os mais recentes, em inglês (Walter Benjamin: Images, the Creaturely, and the Holy. Stanford University Press,2013); o volume coletivo de Peter Wagner Icons-Texts-Iconotexts. Essays on Ekphrasis and Intermediality (Berlin-New York, W. de Gruyter, 1996), uma antologia crítica de Beate Allert, Languages of Visuality: Crossings between Science, Art, Politics, and Literature (Wayne State University Press, 1996) ou o volume de Jeff Morrison e Florian Krobb, Text Into Image: Image Into Text (Rodopi, 1997). É um debate forte na tradição anglo-americana, mas nem tão relevante na tradição latina (latino-americana ou latino-europeia). Creio que porque, na primeira, impera a problemática da ekfrasis e, na segunda, uma abordagem estética que poderíamos simplificar, e nomear, com a frase de Magritte, "Ceci n'est pas une pipe". Na primeira, pace Auerbach, entre outros, predomina a abordagem autonomista do literário, o imperativo categórico da mimesis. Na segunda, porém, um pensamento da heterogeneidade dessas esferas, em relação à esfera propriamente política, traça uma tradição muito precisa que passa, no entanto, por Mallarmé ("impersonnifier le volume"), Duchamp (o infraleve), Bataille (o acéfalo). Mas esta segunda vertente (e não a primeira) é a que nos permite pensar que, não podendo ser fundada sobre um princípio transcendente, como o Belo universal, a estética, a aisthesis como contato, é necessariamente fundada, ou antes, infundada, sobre a ausência de uma natureza humana, de uma convenção, de uma comunidade.

Creio que, nessa deriva, onde agem não só o poder, mas também a pulsão de domínio e, correlativamente, uma deliberada pulsão de subordinação, tocam-se perigosamente barbárie e cultura, o que sinaliza, eloquentemente, a indeterminação e a abertura dinâmicas que, no mundo de hoje, tanto levam à vida quanto à morte. Essa forma de vida aí desenhada não responde, a princípio, a nenhum destino ou projeto que a preceda. Daí que mal se poderia aplicar o princípio clássico de ut pictura poiesis. Essa indeterminação é tão individual quanto coletiva, na medida em que a existência (do estético, por exemplo) só se verifica conforme a pluralidade 
dos singulares em que se dissolve toda postulação de uma unidade do ser. A singularidade da literatura (Derek Attridge) exige que uma política, mais do que uma simples ética, faça emergir claramente o fato de que suas questões acerca do sentido ultrapassam largamente a esfera de seu governo, o que em última análise coloca o tema do comum ou do em-comum em jogo.

O comum (que a rigor não possuímos jamais) é, contudo, o regime do mundo: fazer circular os sentidos. Da imagem ao texto, do texto à imagem. Mas a esfera do comum não é unitária: ela é feita de múltiplas aproximações da ordem do sentido, que é, por sua vez, ela mesma, múltipla, já que, segundo Jean-Luc Nancy, As Musas (plural) regulam a Arte (singular). Não se trata, absolutamente, de postular um regime de forma, ideal e a priori, que transmitisse o sentido abrindo-se sobre os outros por contato ou por envio, por contraste ou analogia, seja de forma reta, oblíqua ou quebrada. O todo do estético ao contrário, exige um mais que todo, um pas au-delà, seja ele vazio ou silêncio, anestético, sem o qual o próprio todo se torna inviável. A literatura designa então a contingência de uma humanidade exposta à ausência de todo fim dado, mas nem por isso desprovida de infinito. É, portanto, nessa dupla condição de exposta porém existente que deveríamos pensá-la. Subtraída da idolatria pessoal da mimesis, a literatura do impessoal torna-se sinal da pessoa singular-plural, omnes et singulatim, como queria Foucault, compreendida, politicamente, como a pessoa que, na própria ação política, abre-se, quase biologicamente, ao conflito entre imunidade e dom.

Mas se V. não quiser uma linhagem “estrangeira”, como a de Mallarmé, Duchamp, Magritte ou Bataille, poderia fornecer uma tradição local. Certamente um lugar de destaque caberia a Clarice Lispector. Em uma página de Água viva, ela diz, a propósito,

Entro lentamente na escritura assim como já entrei na pintura. É um mundo emaranhado de cipós, sílabas, madressilvas, cores e palavras - limiar de entrada de ancestral caverna que é o útero do mundo e dele vou nascer. E se muitas vezes pinto grutas é que elas são o meu mergulho na terra, escuras mas nimbadas de claridade, e eu, sangue da natureza - grutas extravagantes e perigosas, talismã da Terra, onde se unem estalactites, fósseis e pedras, e onde os bichos que são doidos pela sua própria natureza maléfica procuram refúgio. As grutas são o meu inferno.

A concepção é absolutamente idêntica à de Bataille, em seu ensaio Organon, Porto Alegre, v. 31, n. 61, p. 305-313, jul/dez. 2016. 
sobre Lascaux, onde indaga a origem da arte, que é por sinal um ensaio contemporâneo de um outro, igualmente brilhante, o de Olympia. E o que mais me interessa destacar, nesse último texto, é que Bataille propõe a emergência do moderno justamente não a partir do gesto de pintar o prostíbulo, mas a partir da recusa a descrever qualquer objeto. Olympia abre o moderno porque o quadro abole a anedota. Oblitera o assunto. Não é o texto o que conta e sim o gesto. Dissipação, dispêndio ou seja, negatividade. Em poucas palavras, poderíamos postular Sade como o autêntico fundador da modernidade. Mas, da mesma forma, digamos assim, sadeana, não haveria Clarice nos anos 70 sem a refutação da ekfrasis modernista encarada, já nos anos 30 (quando aliás começa o contemporâneo) por Flávio de Carvalho. Ele sintomaticamente argumenta em um ensaio de 34 que, do ponto de vista psicológico, a pintura se divide em duas classes: uma que mostra as emoções primárias resgatáveis nas profundezas mais íntimas do homem, ou seja, nas grutas de Clarice, e a outra que mostra, como elementos em evidência, somente as emoções secundárias. A pintura que contém as emoções primárias é uma pintura demoníaca, altamente salutar porque mergulha o homem em sonho e pensamento, porque faz ele sentir o tumulto da sua gênese e, mais ainda, a beleza desse tumulto. A outra, a pintura dominada pelas emoções secundárias, é uma pintura operativa e essencialmente fútil. É operática, nos diz Flávio, porque procura representar um drama sob forma melódica, drama esse em que cada elemento é altamente expandido e reiteradamente encenado. O desafio é um drama visual que pertence à superfície mais externa dos acontecimentos corriqueiros e esse tipo de pintura é frequentemente aceito como uma fórmula religiosa que pode ser assistida e repetida, diariamente, sem perturbar ninguém, porque não contém nada de particularmente perturbador, nem nada que possa excitar o pensamento e suscitar novas respostas, mesmo que seja de uma parte ínfima do espantoso demoníaco do inconsciente. A pintura operática, completa Flávio, não está somente livre dos perigos do inconsciente e das traições do poetismo; ela é uma pintura que, pela sua natureza de tagarelice melódica e pela sua gesticulação histérica, há de se valer da forma não para exprimir as forças da alma, mas apenas a futilidade das emoções secundárias.

LR: De certo ponto de vista, as linguagens sempre dialogaram entre si. O teatro, a ópera, por exemplo, já nascem como um diálogo entre diferentes expressões. Hoje, todavia, parece ter-se criado uma nova mentalidade e uma nova liberdade de criação artística. Como você analisa esse processo? 
RA: Justamente um ano depois desse ensaio que citava agora há pouco, em seu livro Os ossos do mundo, recentemente resgatado, Carvalho completaria o paradigma, dizendo que a pintura italiana, isto é, a Renascença e tudo o que dela deriva (o humanismo, a perspectiva e....a literatura comparada) é toda ela marcada pelo traço epidêmico do que Flávio chama "Madona e Bambino", uma sorte de Pathosformel da moderna tradição sensível em nossa área cultural. Ele está descrevendo um conjunto de pinturas para as igrejas e, portanto, pintura para as massas, "histórias em quadrinhos". Trata-se, em outras palavras, de pintura operática, de acentuada declamação lírica. E esta característica permite-lhe pensar que, na medida em que a ópera é o espetáculo predileto das massas, desde os primórdios do século $\mathrm{V}$, com as Virgens Loucas e as Virgens Bem-Comportadas, até o século $\mathrm{XV}$, quando se consolida como gênero nacional (e relembremos que as reflexões contemporâneas de Gramsci sobre o nacional-popular passam, no caso da Itália, especificamente pela ópera), essa nova linguagem girou em torno do problema sexual religioso, Deus, Filho, Espírito Santo, Virgem, que era o drama lírico do pequeno círculo familiar, acessível, portanto, à compreensão das massas.

Nesse raciocínio sobre uma arqueologia da sensibilidade na tradição latino-europeia, Flávio de Carvalho não pode esconder um enorme fascínio pelo primitivo e pelo místico que, de certo modo, compartilha com a etnologia de Lévy-Bruhl, a dimensão metafísica de Henri Bergson e até mesmo com a experiência interior de Georges Bataille, à qual poderíamos até acrescentar a contribuição de Roger Bastide, contrária à perspectiva patológica do sagrado. Mas se é essa a tradição operática, da qual o modernismo oficial, no Brasil, ainda é tributário nos anos 30, a arte moderna, pelo contrário, é para Flávio não-operática. A proverbial operação destruidora da Musa, em Mallarmé, é um modo possível de conduzir a linguagem estereotipada da ekfrasis à torrente da fala tagarela, que longe de se acomodar nas previsíveis contenções da forma e da autonomia, permite, em compensação, a emergência da política, pelo simples motivo de que a política corresponde à inoperosidade essencial dos homens. Depois de Heidegger e dos pós-heideggerianos como Lacan ou Foucault, diríamos que só existe o humano na medida em que o homem é um ser argós, alguém a quem nenhuma operação ou atividade consegue definir por completo. É um ser de pura potência, que nenhuma identidade pode apreender, de tal sorte que a questão moderna por excelência é, em poucas palavras, a questão do in-operático, a dimensão do désoeuvrement, a condição argós do homem na pós-história, algo que podemos reconhecer no voyou désoeuvré, o 
individuo inoperoso de Raymond Queneau, a comunidade inoperante em Nancy ou a vida nua de Agamben.

Uma das escritoras mais agudas da cena contemporânea, a gaúcha Verônica Stigger, autora de Opisanie Swiata, fundamenta sua leitura do acervo do Museu de Arte Moderna de São Paulo, em recente exposição, apelando a Oswald de Andrade, quem dizia ter "o coração menstruado" e que, ao criar, sentia "uma ternura nervosa, materna, feminina", que se descolava dele, "como um jorro lento de sangue". "Um sangue que diz tudo, porque promete maternidades. Só um poeta é capaz de ser mulher assim”. A partir de Oswald, Verônica aventa que o princípio feminino, histérico mesmo, é na arte uma força tão poderosa e transformadora que pouco importa se o artista nasceu homem ou mulher. E é justamente no capítulo esquecido ou perdido de Opisanie Swiata, por ela lido no Museu de Arte do Rio de Janeiro, em 2012, que toda a troupe modernista decide montar uma ópera, certamente bufa, ubuesca, que só uma testemunha muda compreenderia muito tempo depois, quando todos os atores da pantomima estivessem já mortos. Opalka, mas não a personagem de Stigger senão o artista plástico polonês (embora nascido na França) Roman Opalka, diria que a matéria de toda imagem é o tempo. E nisso coincidiriam Germano Celant ou Peter Osborne. Os autorretratos de Opalka, com efeito, fotografias frontais, preto e branco, do próprio artista olhando para a objetiva, tomados a partir de 1965, são instantes de inoperância. Bió-grafo, ou seja, cinema. "Ce que je nomme mon autoportrait, diz Opalka, est composé de milliers de jours de travail. Chacun d'eux correspond au nombre et au moment précis où je me suis arrêté de peindre après une séance de travail". Imagem sabática. Diabólica ou demoníaca. O abandono do labor.

LR: A discussão sobre a apropriação de textos literários para o cinema, por exemplo, traz à discussão não só o específico da linguagem cinematográfica, como também a fidelidade do filme com a obra literária. Diante disso, você pode tecer algumas considerações sobre a relação do texto literário com o cinematográfico?

RA: Cinema é Godard e Godard, numa entrevista, nos diz que, na literatura, há muito passado e um pouco de futuro, mas não há nada de presente. No cinema, porém, só há presente, que não faz mais do que passar. Quer dizer que, na tela, o presente é aquilo que nos é apresentado no mesmo momento em que desaparece, e o mesmo se dá com outros procedimentos, escrever, pintar, pensar... Vanishing present, segundo Jameson. Mas para 
dar uma genealogia precisa a Godard, teríamos de lembrar de Mallarmé: penser étant écrire sans accesoires. De fato, para a linhagem de Godard, à qual poderíamos acrescentar também Harun Farocki ou Edgardo Cozarinsky, o cinema é sempre um estrangeiro, um imigrante, um criado. $\mathrm{O}$ cinema está sempre sozinho, enquanto as outras linguagens vão sempre juntas. Todo o esforço do cinema de Godard, a meu ver, é tornar visível, buscando criticar a prática de dar a ver e, ainda por cima, transformar a relação entre sujeito e objeto (Adorno), para que se constate até que ponto é invisível a visibilidade do visível (Foucault). Certamente, a aposta de Godard é a mais consistente no sentido de apontar por essa via, a da imagem, as relações entre cinema e história. Jacques Rancière, analisando o tópico, diz que a dele é uma forma de reabrir a agenda colocada pela poesia no século XIX ou, se preferirem, de repensar as relações entre mythos e logos, entre religião e ciência, porque há duas maneiras de acertar as contas com a religião-diz Rancière-a primeira consiste em dizer: baixemos a este mundo tudo o que se acha no céu, transformemos em realidade todos os projetos dos homens esboçados no céu da religião. Essa é a maneira que triunfou. A realista. O populismo de direita. Mas há a atitude inversa, segundo a qual somente uma única coisa deve ser reivindicada à religião: 0 movimento de Elevação, de afastamento ou de projeção. A utopia. Não se trata então de reconduzir o distante para a esfera do próximo, mas sim de projetar o homem o mais longe possível de si mesmo, a ponto de fazer com que uma outra luz possa iluminar sua passagem pelo mundo.

Ora, essa segunda maneira foi formulada, no século 19, por Mallarmé, um contemporâneo de Manet e de Wagner. E essa perspectiva é também a leitura mallarmeana de um discípulo de Alain Badiou, Quentin Meillasoux. Ao escutar então as diversas vozes presentes nas História(s) do Cine$m a$, por exemplo, mesmo um dialético como Rancière detecta um empreendimento idêntico: conferir à ficção um sentido puramente humano, livre daquilo que Mallarmé chamou de "iguaria bárbara da Eucaristia". Ou seja, separar a ficção do mito. Contrapor à figura, na qual nos reconhecemos, aquilo que Mallarmé chamou de "a figura que não está em lugar algum, pura metáfora de nossa forma”. Conferir à ficção o estatuto de uma pura projeção. Fixar uma constelação improvável sobre uma superfície disponível e superior. É essa a leitura mallarmeana de Rancière ou Meillassoux.

Mais ainda. Retomando, nesse sentido, o que Foucault diz em seu ensaio sobre "Aspecto, distância, origem", Rancière argumenta que o cinema não é nem uma arte nem uma técnica, mas um mistério. E esse é um termo totalmente clariceano: perseguir na arte o objecto-relatório-mistério. 
Objecto com c, à maneira arcaica, portuguesa. O passado da linguagem que sobrevive. Rancière defende então o mistério com o argumento de que Mallarmé conferiu um sentido novo à palavra, sentido no qual se condensam três significados diferentes. Primeiro, o jogo das formas responsável pela analogia (a comparação!) entre a interioridade e o teatro no mundo. Segundo, o invisível puramente humano, característico da vida laica. E, finalmente, o invisível situado à distância, seu mistério, sua ficção. Não o divino recuperado, mas sim o homem projetado, potencializado. Em poucas palavras, para pensarmos nos termos de Mallarmé, o homem é, na verdade, um animal quimérico que deve reconhecer-se enquanto tal, como animal quimérico. É o único animal que vai ao cinema (Agamben). Se devolvemos então potência ao ato (neológico) de imager, como diz Nancy, nos encontramos, no fundo das imagens, que aí está o ideograma mallarmaico, constelacional, de dispor ao redor do sufixo -mage os prefixos $i$ - dom- fro- ra- plu- hom- com o qual teríamos imagem-pena-queijo-ramagem-plumagem-homenagem, ou seja, um fantástico exercício de atribuição errônea, como o que Marcel Duchamp já destacava, em Le Dessin dans l'art magique: uma raiz imaginária entre -mage e magia, a ação espectral do maccelaio, o magarife, o açougueiro. Trocando em miúdos, onde há imagem, há distância, há corte e há montagem.

LR: Na sua produção atual, você tem desenvolvido alguma reflexão sobre o estudo interartes e/ou intermídias?

RA: É talvez o foco principal de Maria com Marcel: Duchamp nos trópicos (2010), onde me deparo, como dizia Clarice, com "um mundo emaranhado de cipós", o imaginário amazônico de Maria Martins e a acefalidade de Duchamp, plenitude e esvaziamento. O esforço continuou em Imágenes de América Latina (2014) e nas Archifilologías latinoamericanas. Lecturas tras el agotamiento (2015). Mesmo em obras em que a problemática da imagem é tangencial, como na edição crítica de O Ateneu (2015) ou na mais recente, A ruinologia (2016), a questão sempre aparece, porém sempre também sob um prisma anestético. Para retomarmos a mesma linha de raciocínio de Godard ou Opalka, gostaria de relembrar o pintor espanhol Antonio Saura, grande admirador de Jackson Pollock, quem considera que $O$ cachorro afundando na areia, o célebre quadro de Goya, pintado quase às vésperas da loucura e da sua viagem derradeira à França, é a maior tela da modernidade. Trata-se de uma visão, para além do espelho, em forma de cabeça de cachorro, suspensa na paisagem dourada do nada celestial. Nada mais 
absurdo que este quadro, sedutor de tantos escritores, de Malraux a Todorov, passando por Ortega y Gasset, Valeriano Bozal, Jean Louis Scheffer e tantos outros, que é uma tela anacrônica, que antecipa Turner e também os impressionistas franceses, pois só representa a pintura para dizer, precisamente, que é o paradigma da condição humana e da própria arte moderna. Uma última aparição, diz Saura, um desaparecimento mal e mal disfarçado, mera hallucination éparse d'agonie, como diria Mallarmé. Um adeus à pintura que, em seu interior, traz uma mensagem. Não sou um cachorro: sou seu autor e também todos quantos contemplarem este quadro. Porque acima de tudo sou pintura e, sem ela, sem uma linguagem que me porta e transporta, eu mesmo não existiria. Ora, Alain Badiou, em seu seminário de 2007 sobre Duchamp, destaca como uma das maiores contribuições à estética da aparição / desaparecimento, aquilo que ele chama point de pensée e que podemos entender como ponto de pensamento, no sentido em que Lacan falava de ponto de capitonné, isto é um nada de pensamento, uma ausência de razão, uma exceção que dis-pensa em in-operância. O paradigma desse point de pensée seria, a seu ver, uma imagem mallarmaica, "une rose dans les ténèbres", expressão que reencontraremos, como epígrafe da "Tristura" urbana, em um dos poemas de Pauliceia Desvairada, mas que teria talvez sua melhor equivalência brasileira na basculação flor/náusea de Drummond. Algo semelhante à beleza convulsiva: "É feia. Mas é uma flor. Furou o asfalto, o tédio, o nojo e o ódio". Creio que esses exemplos todos nos ilustram, para retomarmos o raciocínio de Badiou, que a arte contemporânea é uma arte satisfeita com seu próprio desaparecimento, uma arte robusta em sua disposição para desaparecer, firme na sua contingência, que é, justamente, o oposto da arte clássica, arte da contemplação, arte do duradouro ou definitivo, porque aquilo que se contempla é justamente o que não desaparece. Daí a relevância, na arte contemporânea, da imagem artificial, do vídeo, da performance. São todas artes da imagem em movimento que nos persuadem de uma lição muito importante na arte contemporânea: nela, o passado é relembrado pela memória, mas é repetido pela matéria. É disso do que se trata na sobrevivência das imagens. Se Duchamp (e Lacan, com sua pulsão escópica) nos ensinaram a ver-se vendo, o desafio agora é ver-se lendo.

Recebido em: 08/06/2016. Aceito em: 23/08/2016. 